\title{
Current approaches in the grading and management of cytokine release syndrome after chimeric antigen receptor T-cell therapy
}

This article was published in the following Dove Press journal:

Therapeutics and Clinical Risk Management

\section{Lara L Riegler' \\ Gavin P Jones ${ }^{2}$ \\ Daniel W Lee'}

'Division of Pediatric Hematology/ Oncology, Department of Pediatrics, University of Virginia, Charlottesville, VA, USA; ${ }^{2}$ School of Medicine, University of Virginia, Charlottesville, VA, USA
Correspondence: Daniel W Lee Division of Pediatric Hematology/ Oncology, Department of Pediatrics, University of Virginia, PO Box 800386, Charlottesville, VA 22908, USA

Tel + I 4342974289

Email dwl4q@virginia.edu

\begin{abstract}
With immunotherapy innovations for cancer treatment, in particular chimeric antigen receptor (CAR) T cells, becoming more successful and prevalent, strategies to mitigate and manage their toxicities are required. Anti-CD19 CAR T-cell therapy has revolutionized the treatment of relapsed/refractory pediatric and adult acute lymphoblastic leukemia and refractory adult non-Hodgkin lymphoma, resulting in the expanded use of CAR T cells in multicenter trials and as US FDA-approved products. Cytokine release syndrome (CRS) and CAR-associated neurotoxicity, which can occur independently or concurrently with CRS, are two potentially life-threatening toxicities of CAR T-cell therapy. In this review, we will focus on describing the pathophysiology behind CRS, the proposed definitions of and grading systems for CRS, and innovative options for treating this potentially lethal systemic inflammatory condition.

Keywords: adoptive cellular immunotherapy, CD19 CAR T cells, tocilizumab, CAR-associated neurotoxicity, Immune Effector Cell-Associated Neurotoxicity Syndrome, leukemia
\end{abstract}

\section{Introduction}

For decades, the pillars of cancer treatment have been surgery, chemotherapy, and radiation therapy. But with the successful introduction of targeted therapies, such as tyrosine kinase inhibitors and monoclonal antibodies, the field of oncology began to evolve. More recently, remission in patients with previously incurable malignancies has been achieved with cutting edge immunotherapies such as chimeric antigen receptor (CAR) T-cell therapy and bispecific antibody-based immune engagers. But the toxicities of these innovative new therapies, especially cytokine release syndrome (CRS) and neurotoxicity, must be managed.

Although survival rates in standard risk pediatric acute lymphoblastic leukemia (ALL) approach $90 \%$ using traditional chemotherapy, patients with refractory or recurrent ALL have dismal survival with chemotherapy and even bone marrow transplant. ${ }^{1,2}$ In addition, up to $60 \%$ of childhood cancer survivors experience significant late effects from their chemotherapy, including neuro-cognitive effects, cardiotoxicity, infertility issues, and secondary malignancies ${ }^{3}$ making the case for the need to develop new therapeutic approaches. Adults with ALL or relapsed chronic lymphocytic leukemia (CLL) fare significantly worse as do those with relapsed or refractory non-Hodgkin lymphoma (NHL). ${ }^{46}$

CAR T-cell therapy requires harvesting and then genetically engineering the patient's own $\mathrm{T}$ cells to recognize specific antigens on the surface of tumor cells. ${ }^{7}$ The tumor antigen most often targeted in successful trials to date is CD19 as it is almost universally expressed on B-lineage leukemias/lymphomas. ${ }^{8}$ A CD19-directed 
CAR allows the T cells to bind specifically to tumor cells, initiating the cytotoxic sequence of events leading to the destruction of these malignant cells. A number of cytokines are produced by this superactivation of $\mathrm{T}$ cells, which are responsible for the majority of CAR toxicities. ${ }^{9}$

Inflammatory cytokines are small, secreted proteins necessary for immune cell signaling, activation, and recruitment of other inflammatory cells. These can be secreted by the CAR T cells themselves or by other immune effector cells activated by circulating cytokines. ${ }^{10}$ CRS has been defined as a systemic inflammatory state that occurs due to robust and widespread immune activation induced by a cellmediated immune response. ${ }^{9}$ The National Cancer Institute defines CRS as a condition that may occur after treatment with some types of immunotherapy, such as monoclonal antibodies and CAR T cells, caused by a large, rapid release of cytokines into the blood from immune cells. Though the original clinical definition of CRS included symptoms of neurotoxicity, ${ }^{9}$ neurotoxicity is currently considered an independent event as the two are known to occur separated in time from each other.

Considerable insights into the pathophysiology of CRS, without the background of malignant disease, were obtained in 2006 during a Phase I clinical trial of TGN1412, an anti-CD28 monoclonal superagonist antibody that directly stimulates T cells. ${ }^{11}$ Six healthy adults received the monoclonal antibody simultaneously. All six volunteers rapidly developed a systemic inflammatory response with symptoms of severe headache, myalgias, nausea/vomiting, fever, tachycardia, and hypotension. Within the first 24 hours after antibody infusion, all six subjects became critically ill with pulmonary infiltrates, acute respiratory distress, renal failure, and disseminated intravascular coagulation. No infections, endotoxins, or underlying diseases were identified in any of these volunteers suffering from multiorgan failure. All six study participants required aggressive treatment in the intensive care unit, which included intensive cardiopulmonary support, high-dose methylprednisolone, dialysis, and an anti-IL-2R antagonist antibody. Due to these extensive interventions, all of the study participants survived despite the severity of their toxicities. These events represent perhaps the first severe CRS events to be observed.

CD19-directed CAR T cells represent a paradigm-changing approach in treating B-cell malignancies. Extremely high complete response (CR) rates have been reported in several single and multicenter trials for the treatment of refractory ALL and NHL with CAR T-cell therapy. ${ }^{12-20}$ In August 2017, the first CAR T-cell therapy, tisagenlecleucel, was approved by the US Food and Drug Administration (FDA) for the treatment of pediatric ALL. ${ }^{21}$ Two months later, the second CAR T-cell therapy, axicabtagene ciloleucel, was FDA-approved for treatment of relapsed or resistant adult NHL $^{22}$ followed in early 2018 by tisagenlecleucel again for the same population. ${ }^{23}$ Given the high incidence of severe and life-threatening CRS with these therapies, the FDA also simultaneously approved tocilizumab for the management of severe CRS. ${ }^{24}$

\section{Symptoms and early grading of CRS}

CRS is a systemic inflammatory response caused by the release of inflammatory cytokines, such as IL-6, interferon gamma (IFN $\gamma$ ), tumor necrosis factor alpha (TNF $\alpha$ ), IL-2, and IL-10, by large number of activated lymphocytes (B cells, $\mathrm{T}$ cells, and/or natural killer cells) and/or myeloid cells (macrophages, dendritic cells, and monocytes) which can lead to a constellation of clinical symptoms including fever, hypotension, and widespread organ dysfunction (Figure 1). ${ }^{9}$

The clinical effects of CRS can range from mild flu-like symptoms, with fever and myalgias, to a severe inflammatory syndrome. Severe CRS can cause vascular leak, hypotension, pulmonary edema, cardiac dysfunction, renal impairment, hepatic failure, coagulopathy, multiorgan system failure, and even death. ${ }^{9,12-20}$

Several attempts to develop a consistent and consensusbased grading system for CRS have occurred as CAR T-cell therapy has evolved. Such a uniform and universal grading system would, ideally, allow for objective assessment of patients with CRS, improve the interpretation of CAR-related adverse-related events across different studies, and help guide appropriate treatment strategies in patients.

Initially, CAR T-cell induced CRS was graded according to the Common Terminology Criteria for Adverse Events version 4.03 (CTCAEv4.03), which included a grading scale of CRS-related adverse events caused by immunotherapies (Table 1). ${ }^{25}$ This scale, originally developed prior to the advent of CAR T-cell clinical trials, was meant to assess the acute infusional toxicities of monoclonal antibodies rather than cellular therapies, and therefore was not an ideal framework by which to grade CRS resulting from CAR T-cell therapy. It was predicated on the idea that symptoms of CRS develop within minutes to hours of antibody infusion and that CRS could resolve or improve simply by stopping the infusion of the drug. ${ }^{25}$ This does not accurately reflect the pathophysiology of exponential CAR T-cell in vivo expansion over days following a single, 15-30-minute infusion of cells, nor the more prolonged temporal course 


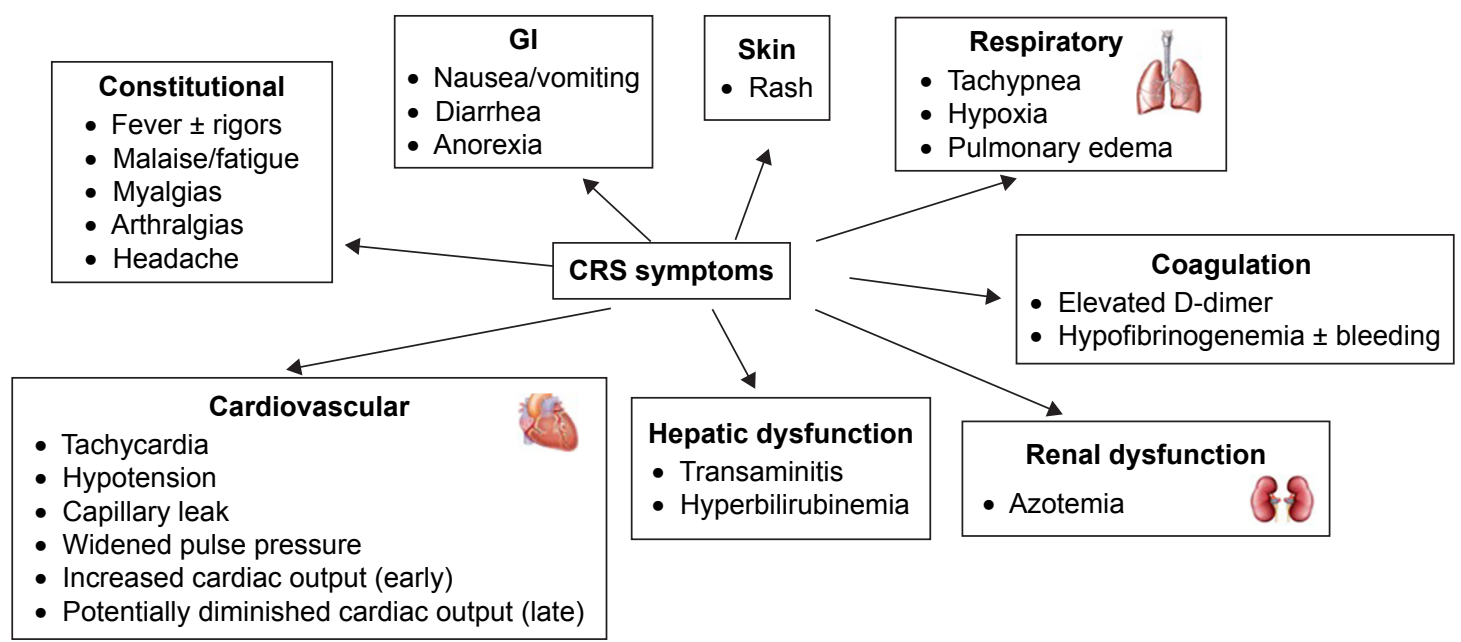

Figure I Symptoms of CRS.

Notes: CRS affects a number of organ systems. It requires fever at a minimum but is frequently associated with any of the symptoms shown. Additional manifestations may also rarely occur.

Abbreviations: GI, gastrointestinal; CRS, cytokine release syndrome.

of CAR T-cell induced CRS, which the scientific literature currently supports. The most recent CTCAE v5.0 has modified its original criteria to reflect this knowledge and will be discussed later.

\section{Proposed CRS grading scale: the Lee criteria} Given its limitations, CRS grading as per CTCAEv4.03 was subsequently modified by Lee et al to define mild, moderate, severe, and life-threatening CRS regardless of the inciting agent, and to more directly guide treatment recommendations (Table 2). ${ }^{9}$ This modified scale was developed in the context of ongoing anti-CD19 CAR T-cell clinical trials and takes patients' response to intravenous fluids (IVFs) and vasopressors, oxygen requirement, and organ toxicities into account. The authors of this new grading scale emphasized the importance of appropriate clinical judgment in its use. Ultimately, it is up to the discretion of the treating physician to confirm that the symptomatology present is most likely due to CRS, rather than another comorbid medical condition seen in this patient population such as febrile neutropenia, bacterial sepsis, or tumor lysis syndrome.

Under this modified grading system, grade 1 CRS, consisting of fever with or without constitutional symptoms, require supportive treatment measures only such as empiric antibiotics as per routine for fever and neutropenia, antipyretics and antiemetics, blood product transfusions as appropriate, and maintenance of adequate hydration. Such supportive care should be implemented for all degrees of CRS.

Grade 2 CRS occurs when the patient is confirmed to be hypoxic and returns to normoxia using up to $40 \% \mathrm{FiO}_{2}$ of oxygen supplementation, has grade 2 organ dysfunction, or has hypotension responsive to IVFs or a low dose of one vasopressor. Of note, frequent measurement and monitoring of ejection or shortening fraction $(\mathrm{EF} / \mathrm{SF})$ should be

Table I CRS grading as per CTCAE versions 4.03 and 5.0

\begin{tabular}{|c|c|c|c|c|c|}
\hline & Grade I & Grade 2 & Grade 3 & Grade 4 & Grade 5 \\
\hline Version 4.03 & $\begin{array}{l}\text { Mild reaction; infusion } \\
\text { interruption not } \\
\text { indicated; intervention } \\
\text { not indicated }\end{array}$ & $\begin{array}{l}\text { Therapy or infusion } \\
\text { interruption indicated, } \\
\text { but responds promptly to } \\
\text { symptomatic treatment } \\
\text { (antihistamines, NSAIDS, } \\
\text { narcotics, IV fluids); } \\
\text { prophylactic medications } \\
\text { indicated for } \leq 24 \text { hours }\end{array}$ & $\begin{array}{l}\text { Prolonged (eg, not rapidly responsive } \\
\text { to symptomatic medication and/or } \\
\text { brief interruption of infusion); } \\
\text { recurrence of symptoms following } \\
\text { initial improvement; hospitalization } \\
\text { indicated for clinical sequelae } \\
\text { (such as renal impairment, } \\
\text { pulmonary infiltrate) }\end{array}$ & $\begin{array}{l}\text { Life-threatening } \\
\text { consequences; pressor } \\
\text { or ventilatory support } \\
\text { indicated }\end{array}$ & Death \\
\hline Version 5.0 & $\begin{array}{l}\text { Fever, with or } \\
\text { without constitutional } \\
\text { symptoms }\end{array}$ & $\begin{array}{l}\text { Hypotension responding } \\
\text { to fluids. Hypoxia } \\
\text { responding to }<40 \% \mathrm{FiO}_{2}\end{array}$ & $\begin{array}{l}\text { Hypotension managed with one } \\
\text { pressor. Hypoxia requiring } \geq 40 \% \\
\mathrm{FiO}_{2}\end{array}$ & $\begin{array}{l}\text { Life-threatening } \\
\text { consequences; urgent } \\
\text { intervention needed }\end{array}$ & Death \\
\hline
\end{tabular}

Abbreviations: CRS, cytokine release syndrome; CTCAE, Common Terminology Criteria for Adverse Events; IV, intravenous. 
Table 2 CRS grading system developed by Lee et al

\begin{tabular}{|c|c|c|c|c|}
\hline Grade I & Grade 2 & Grade 3 & Grade 4 & Grade 5 \\
\hline $\begin{array}{l}\text { Symptoms are not } \\
\text { life-threatening and } \\
\text { require symptomatic } \\
\text { treatment only (fever, } \\
\text { nausea, fatigue, } \\
\text { headache, myalgias, } \\
\text { malaise) }\end{array}$ & $\begin{array}{l}\text { Symptoms require and respond to } \\
\text { moderate intervention: } \\
\text { I. Oxygen requirement }<40 \% \mathrm{FiO}_{2} \\
\text { OR } \\
\text { 2. Hypotension responsive to } \\
\text { IV fluids or low dose of one } \\
\text { vasopressor } \\
\text { OR } \\
\text { 3. Grade } 2 \text { organ toxicity }\end{array}$ & $\begin{array}{l}\text { Symptoms require and respond to } \\
\text { aggressive intervention: } \\
\text { I. Oxygen requirement } \geq 40 \% \mathrm{FiO}_{2} \\
\text { OR } \\
\text { 2. Hypotension requiring high dose } \\
\text { or multiple vasopressors } \\
\text { OR } \\
\text { 3. Grade } 3 \text { organ toxicity or grade } 4 \\
\text { transaminitis }\end{array}$ & $\begin{array}{l}\text { Life-threatening symptoms: } \\
\text { I. Requirement for } \\
\text { ventilator support } \\
\text { OR } \\
\text { 2. Grade } 4 \text { organ toxicity } \\
\text { (excluding transaminitis) }\end{array}$ & Death \\
\hline
\end{tabular}

Notes: Organ toxicities refer to CTCAE version 4.03. Reprinted from Lee DW, Gardner R, Porter DL, et al. Current concepts in the diagnosis and management of cytokine release syndrome. Blood. 20|4; I24(2): I88-195.'

Abbreviations: CRS, cytokine release syndrome; CTCAE, Common Terminology Criteria for Adverse Events; IV, intravenous.

implemented as sudden decreases in EF/SF can occur independently of hypotension and can trigger upgrading of CRS based on this end-organ dysfunction. Appropriate supportive care should be implemented, and in older patients or those with a significant medical comorbidity, anti-cytokine therapy should be initiated.

Grade 3 CRS includes oxygen supplementation at $\geq 40 \%$ $\mathrm{FiO}_{2}$ for the management of confirmed hypoxia, hypotension requiring high-dose or multiple vasopressors, grade 4 transaminitis, or other grade 3 organ toxicity. As before, supportive care should be provided along with anti-cytokine therapy in every patient. The overarching goal of this management approach is to avoid grade 4 toxicity.

Grade 4 CRS is defined as life-threatening symptoms requiring ventilator support or grade 4 organ toxicity other than transaminitis. Per the treatment algorithm, anti-cytokine therapy should be employed.

Lee et al's grading scheme represents a pivotal paradigm shift from the guidelines provided by the CTCAEv4.03, as it employs more concrete, precise medical metrics (such as oxygen requirement and hemodynamic status) upon which to characterize CRS and to consider treatment options. Although the parameters in the Lee grading system and others are objective, there is still variability among health care providers in how they utilize measurements and apply interventions. For example, clinical judgment is involved in the selection and exact dosing of vasopressors and what is considered acceptable vital signs. Despite its more detailed criteria, Lee et al's grading scheme was still created with the intention of guiding clinical judgment, but is not meant to serve as a de facto substitution for the application of clinical acumen.

\section{Proposed CRS grading scale by Davila et al} Another published rating scale for CRS was devised by Davila et al in 2015 and is unique in its integration of cytokine levels with clinical features, dividing CRS into severe and not severe categories. ${ }^{26}$ Criteria for severe CRS under this system are fevers of $38^{\circ} \mathrm{C}$ or greater for at least 3 consecutive days, at least a 75 -fold elevation of two serum cytokines over baseline, or a 250 -fold elevation of at least one serum cytokine over baseline, as well as one clinical sign of severe toxicity. The criteria for clinical signs of severe toxicity are: hypotension (requiring one intravenous vasoactive pressor), hypoxia $\left(\mathrm{SaO}_{2}<90 \%\right)$, or neurologic disorder (including mental status changes, obtundation, and seizures). Although this rating scale may reliably identify CRS patients in need of urgent intervention, its application is significantly limited by issues of practicality, as obtaining real-time, reliable, CLIA-certified cytokine levels is not feasible at most treatment facilities.

\section{Proposed CRS grading scale: the Penn scale}

An alternate CRS grading scale from the University of Pennsylvania (Table 3; the Penn scale) was originally derived from data collected on a cohort of 125 adult and pediatric patients treated with tisagenlecleucel. ${ }^{27}$ The University of Pennsylvania has applied their CRS grading scale to trials involving CLL, ALL, and diffuse large B-cell lymphoma (DLBCL), and plan to grade CRS associated with CAR T-cell targeting antigens other than CD19. ${ }^{27}$

Its major difference from the Lee criteria is that any fluid bolus or vasopressor use for hypotension is considered grade 3 CRS. This schema lacks granularity at this level, treating transient and mild hypotension identical to severe hypotension. Further, grade 2 CRS includes "some signs of organ dysfunction" (which is unclear) and fever and neutropenia, known to occur in the vast majority of leukemia patients, already neutropenic from disease, responding to CAR T-cell therapy. One may argue whether fever and neutropenia constitutes CRS. Finally, patients with hypoxia responsive to trivial amounts of oxygen (eg, $1 / 2 \mathrm{~L} / \mathrm{min}$ of $100 \%$ 
Table 3 University of Pennsylvania CRS grading system

\begin{tabular}{|c|c|c|c|c|}
\hline Grade I & Grade 2 & Grade 3 & Grade 4 & Grade 5 \\
\hline $\begin{array}{l}\text { Mild reaction: treated } \\
\text { with supportive care } \\
\text { such as antipyretics, } \\
\text { antiemetics }\end{array}$ & $\begin{array}{l}\text { Moderate reaction: some signs } \\
\text { of organ dysfunction (grade } 2 \\
\text { creatinine or grade } 3 \text { LFTs) related } \\
\text { to CRS and not attributable to any } \\
\text { other condition } \\
\text { Hospitalization for management of } \\
\text { CRS-related symptoms, including } \\
\text { neutropenic fever and need for } \\
\text { IV therapies (not including fluid } \\
\text { resuscitation for hypotension) }\end{array}$ & $\begin{array}{l}\text { More severe reaction: hospitalization } \\
\text { required for management of symptoms } \\
\text { related to organ dysfunction, including } \\
\text { grade } 4 \text { LFTs or grade } 3 \text { creatinine, } \\
\text { related to CRS and not attributable to } \\
\text { any other conditions } \\
\text { Hypotension treated with multiple fluid } \\
\text { boluses or low-dose vasopressors } \\
\text { Coagulopathy requiring fresh frozen } \\
\text { plasma, cryoprecipitate, or fibrinogen } \\
\text { concentrate } \\
\text { Hypoxia requiring supplemental } \\
\text { oxygen (nasal cannula oxygen, high- } \\
\text { flow oxygen, CPAP, or BiPAP) }\end{array}$ & $\begin{array}{l}\text { Life-threatening } \\
\text { complications such as } \\
\text { hypotension requiring } \\
\text { high-dose vasopressors } \\
\text { Hypoxia requiring } \\
\text { mechanical ventilation }\end{array}$ & Death \\
\hline
\end{tabular}

Abbreviations: CRS, cytokine release syndrome; LFTs, liver function tests; CPAP, continuous positive airway pressure; BiPAP, bilevel positive airway pressure.

$\mathrm{FiO}_{2}$ by nasal cannula) are classified as the same grade of CRS as those requiring continuous positive airway pressure.

\section{Proposed CRS grading scale: CARTOX}

A group led by MD Anderson Cancer Center suggests that CRS should be suspected if at least one of the following four symptoms or signs is present within the first 3 weeks of cellular immunotherapy: fever $\geq 38^{\circ} \mathrm{C}$; hypotension with systolic blood pressure $<90 \mathrm{mmHg}$; hypoxia with an arterial oxygen saturation of $<90 \%$ on room air; and/or evidence of organ toxicity. ${ }^{28} \mathrm{We}$ strongly suggest, however, that the presence of fever is a prerequisite for CRS. As well, the importance of exercising clinical judgment to parse these signs/ symptoms out from other concurrent conditions is emphasized. Neelapu et al propose a grading system for CRS in adults nearly identical to the Lee criteria (Table 4). ${ }^{28}$ It is based on four parameters, three of which are vital signs (temperature, blood pressure, and oxygen saturation) with the fourth being the grade of any organ toxicity detected according to CTCAEv4.03.
Similar to the Lee criteria, the need for low-dose vs highdose vasopressor therapy to control hypotension can be used to distinguish grade 2 from grade 3 CRS, according to the definitions of "high-dose" vasopressors previously reported by Lee et al. ${ }^{9}$ Importantly, however, hemodynamic shock in the setting of CRS is instead evaluated as a dynamic parameter, and not based on static dose requirements for vasopressors. A patient requiring a rapid increase in the dose of vasopressors, or exhibiting evidence of end-organ hypoperfusion, should be treated for grade $3 \mathrm{CRS}$, even if the vasopressor therapy required is "low-dose" by definition. One might argue that grade 2 CRS should apply if a low-dose vasopressor is all that is needed to restore and maintain normal perfusion. Regardless, Neelapu et al suggest that the CRS grade should be determined at least twice daily and at any time when a change in the patient's status is observed.

\section{Proposed CRS grading scale: CTCAEv5.0}

In March 2018, CTCAE v5.0 was released with significantly modified grading criteria for CRS (Table 1) that borrows

Table 4 CRS grading system developed by Neelapu et al

\begin{tabular}{|l|l|l|l|l|}
\hline Symptom/sign of CRS & Grade I & Grade 2 & Grade 3 & Grade 4 \\
\hline Temperature $\geq 38^{\circ} \mathrm{C}$ & Yes & Any & Any & Any \\
\hline $\begin{array}{l}\text { Systolic blood pressure } \\
<90 \mathrm{mmHg} \text { (hypotension) }\end{array}$ & No & $\begin{array}{l}\text { Responds to IV fluids or } \\
\text { low-dose vasopressors }\end{array}$ & $\begin{array}{l}\text { Needs high-dose or } \\
\text { multiple vasopressors }\end{array}$ & Life-threatening \\
\hline $\begin{array}{l}\text { Oxygen requirement for } \mathrm{SaO}_{2} \\
>90 \% \text { (hypoxia) }\end{array}$ & No & $\mathrm{FiO}_{2}<40 \%$ & $\mathrm{FiO}_{2} \geq 40 \%$ & $\begin{array}{l}\text { Needs ventilator } \\
\text { support }\end{array}$ \\
\hline argan toxicities & Grade I & Grade 2 & $\begin{array}{l}\text { Grade 3 or grade 4 } \\
\text { transaminitis }\end{array}$ & $\begin{array}{l}\text { Grade 4 except grade 4 } \\
\text { transaminitis }\end{array}$ \\
\hline
\end{tabular}

Notes: a Cardiac (tachycardia, arrhythmias, heart block, low ejection fraction), respiratory (tachypnea, pleural effusion, pulmonary edema), Gl (nausea, vomiting, diarrhea), hepatic (increased serum ALT, AST, or bilirubin levels), renal (acute kidney injury, increased serum creatinine, decreased urine output), dermatological (rash), and coagulopathy (disseminated intravascular coagulation). Reprinted by permission from Springer Nature: Nat Rev Clin Oncol, Neelapu SS, Tummala S, Kebriaei P, et al, Chimeric antigen receptor T-cell therapy - assessment and management of toxicities, Copyright $2017 .^{28}$

Abbreviations: CRS, cytokine release syndrome; IV, intravenous; GI, ; ALT, alanine aminotransferase; AST, aspartate aminotransferase. 
from the criteria of Lee et al, and takes patients' response to fluids, vasopressors, oxygen requirement, and organ dysfunction into account. ${ }^{29}$ In contrast to the Lee criteria, CTCAEv5.0 defines CRS-related hypotension responsive to IVFs as grade 2 while hypotension requiring any vasopressor as grade 3 . The use of IVF beyond 1-2 boluses was identified as exacerbating pulmonary edema, hypoxia, right-heart strain, and other significant toxicities in the early phases of the first CD19 CAR T-cell trials..$^{9,13,14}$ In fact, one of the justifications for allowing low-dose vasopressors in grade 2 CRS as per the Lee criteria was that physicians would feel free to implement vasopressors early in the CRS course rather than rely heavily on IVF use, thereby minimizing such toxicities. Indeed, many hypoperfusing patients require and respond well to minimal doses of vasopressors.

\section{Lee/Santomasso consensus CRS grading}

In June 2018, the American Society for Blood and Marrow Transplantation sponsored a meeting of over 50 academics, representatives from industry, and other organizations whose goal was to come to a consensus for CRS and CAR-associated neurotoxicity grading. Recently published CRS grading borrows heavily from the Lee criteria with several important differences (Table 5). ${ }^{30}$

As more experience has been gained since 2014 when the Lee criteria were published, it has become clear that hypotension and hypoxia are the two principle drivers of CRS severity. Hence, other organ dysfunction has been removed from the grading criteria. Physicians are also intervening earlier with tocilizumab, many at the time of institution of any dose vasopressor. The 2018 consensus criteria has, therefore, limited grade 2 CRS to IVF management of hypotension only. Low- vs high-dose vasopressor use has been substituted with one pressor with or without vasopressin (grade 3) and two or more pressors except vasopressin (grade 4) in an attempt to make grading and data collection simpler. In regard to oxygen requirements, the 2018 consensus criteria substitute the modality of oxygen delivery for $\mathrm{FiO}_{2}$ as the latter is more difficult to capture for reporting purposes. In general, devices delivering low-flow oxygen are separated in CRS grade from devices delivering high-flow oxygen or positive pressure ventilation.

Now that consensus has been achieved in CRS grading, it is hoped that clinical trials and pharmaceutical companies will all utilize this system allowing a better comparison between different products and populations.

\section{Early identification and prevention of CRS}

Timing of the onset of CRS symptoms and their severity is thought to depend on several factors, including the type of immunotherapy agent used and the degree or capacity of immune cell activation, which varies depending on prior cytotoxic therapies. ${ }^{9}$ In CAR T-cell therapy, the time frame for onset of CRS is days to weeks after cell infusion, when in vivo T-cell expansion is at its peak. What has become clear across all management strategies is that, in general, the earlier anti-cytokine interventions are employed the less likely severe CRS-related toxicities will occur. Early concerns about abrogating the antitumor response or CAR T-cell expansion, at least in ALL, by treating CRS earlier in its course have not borne out.

However, there are no published reports to date of prophylactic anti-cytokine therapy being utilized, that is before the onset of any CRS symptoms including fever. We do not know what role IL-6 or other cytokines affected by such therapies play in the initialization of CAR T-cell expansion and the antitumor response. Also, given that 1) tocilizumab blocks the only naturally occurring mechanism to remove IL-6 from circulation, via endocytosis through its receptor, 2) cytokines including IL-6 have been implicated in CARassociated neurotoxicities, ${ }^{14,31}$ and 3) reports of at least

Table 52018 CRS consensus grading by Lee et $\mathrm{al}^{30}$

\begin{tabular}{|l|l|}
\hline Grade I & Fever $^{\mathrm{a}} \geq 38^{\circ} \mathrm{C}$ \\
\hline Grade 2 & Fever $^{\mathrm{a}} \geq 38^{\circ} \mathrm{C}$ with hypotension not requiring vasopressors and/or hypoxia requiring low-flow nasal cannula or blow-by oxygen \\
\hline Grade 3 & $\begin{array}{l}\text { Fever } \\
\text { cannula, facemask, non-rebreather mask, or Venturi mask not attributable to any other cause }\end{array}$ \\
\hline Grade 4 & $\begin{array}{l}\text { Fever } \\
\text { (eg, } \mathrm{CPAP}, \mathrm{BiPAP}, \text { intubation, and mechanical ventilation) not attributable to any other cause }\end{array}$ \\
\hline Grade 5 & Death \\
\hline
\end{tabular}

Notes: ${ }^{\text {a }}$ ever is defined as temperature $\geq 38^{\circ} \mathrm{C}$. In patients who have CRS then receive tocilizumab or steroids, fever is no longer required to grade subsequent $\mathrm{CRS}$ severity. In this case, CRS grading is driven by hypotension and/or hypoxia.

Abbreviations: CRS, cytokine release syndrome; CPAP, continuous positive airway pressure; BiPAP, bilevel positive airway pressure. 
transient but impressive increases in serum IL-6 levels following tocilizumab, ${ }^{14}$ prophylactic use of tocilizumab may exacerbate or perhaps even instigate neurotoxicity. These issues clearly demand further study, but the presence of adequate pre-clinical models is lacking. Two mouse models of CRS and one non-human primate model of CARassociated neurotoxicity have been recently published but have yet to be validated. ${ }^{32-34}$

Until these issues can be addressed, physicians should take every caution to minimize the risk of CRS to patients. CAR T-cell infusion should be delayed if the patient demonstrates any signs of infection, as they already have a higher basal level of inflammation and cytokine release. There is reliable evidence to suggest that patient age and antigen burden are also risk factors for CRS with older patients and those with higher antigen burden being at increased risk. ${ }^{9,14,35}$

Ongoing research into identifying predictive biomarkers for CRS suggests that although elevations in C-reactive protein and ferritin are associated with CRS, they are not accurate predictors of severe CRS. ${ }^{10,14,24}$ Researchers analyzed levels of 43 cytokines, chemokines, and soluble receptors, to retrospectively predict which patients were most likely to develop severe CRS even before they became critically ill, with the hope of steering future cytokine-directed therapy. ${ }^{24}$ In this study, IFN $\gamma$, IL-6, and sIL-2R $\alpha$ were significantly increased in patients with severe CRS compared to those without, and all patients with grade 4 or $5 \mathrm{CRS}$ had elevations in both IFN $\gamma$ and IL-10. However, many confounding variables such as age, gender, ethnicity, and disease-related factors affect cytokine production making identification of biomarkers for CRS an extremely difficult task. Using cytokines as biomarkers of CRS would also require high-quality laboratory testing with rapid turnaround time, which is not currently available in most hospital laboratories.

\section{Treatment of CRS}

One challenge after diagnosing CRS is determining a therapy which will attenuate the inflammatory cascade without undermining the antitumor effect of the CAR T cells. There is substantial evidence that IL-6, which has both anti-inflammatory and pro-inflammatory properties, is an essential mediator in the signaling cascade of CRS but may also be implicated in the initiation of the antitumor response. ${ }^{12-15,18,36}$

The FDA recently approved tocilizumab for the treatment of severe or life-threatening CAR T-cell-induced CRS in adults and pediatric patients $\geq 2$ years old. ${ }^{24}$ Tocilizumab is a monoclonal antibody that competes with IL- 6 to bind its receptor, IL-6R, thereby inhibiting IL-6 signaling in effector cells. IL-6 signaling occurs through two different mechanisms: via the higher-affinity membrane-bound receptor (classic IL-6 signaling) or via a soluble IL-6 receptor (sIL-6R; trans-IL-6 signaling), both ultimately resulting in activation of the JAK/STAT pathway (Figure 2A and B). ${ }^{37}$ Only certain cells (hepatocytes, macrophages, neutrophils, and T cells) express membrane-bound IL-6R leading to restricted activation during times of low IL-6 levels and mediating its anti-inflammatory properties. In contrast, trans-IL-6 signaling via the soluble receptor predominates at higher levels of serum IL-6 and mediates pro-inflammatory responses. IL-6 bound to the sIL-6R can associate with membrane-bound gp130 resulting in activation of the JAK/STAT pathway. ${ }^{38}$ Since gp130 is broadly expressed across many effector cells, high IL-6 levels result in a more robust immune activation. Tocilizumab blocks both classic and trans-IL-6 signaling through directly binding to membrane-bound IL-6R or the sIL-6R, respectively (Figure $2 \mathrm{C}$ and D). ${ }^{37}$

\section{Timing of tocilizumab administration}

Many immunotherapy experts agree that the timing of CRS treatment should be a clinical decision based on a comprehensive CRS severity grading clinical assessment and not solely on cytokine levels. ${ }^{9}$ It is critical that treating physicians not implement anti-cytokine therapies in the absence of fever, as this is intimately associated with CRS. It is also critical that the physician determines that the patient's symptoms are actually the result of CRS and not another medical condition such as infection, neutropenic sepsis, tumor lysis syndrome, or adrenal insufficiency as anti-cytokine therapy administered under these conditions and without clear evidence of CRS may be detrimental.

The modified grading system devised by Lee et al proposes an approach designed to maximize the therapeutic effect of CAR T-cell therapy while simultaneously minimizing the risk of serious toxicity from CRS (Figure 3 ). ${ }^{9}$ Its aim is to prevent grade 4 or greater CRS through the use of timely therapies. In this algorithm, patients with all grades of CRS require close monitoring and adequate supportive care, with grade 2 or above preferably being monitored in the intensive care unit where hemodynamic function can be closely monitored. Patients with grade $3 \mathrm{CRS}$ need to be treated to avoid progression to grade 4 where potential irreversible organ dysfunction may occur. Tocilizumab should be dosed at $8 \mathrm{mg} / \mathrm{kg}$ (maximum $800 \mathrm{mg} /$ dose) infused over an hour with appropriate premedications. ${ }^{9}$ In the absence of clinical improvement within 24 hours or should rapid deterioration occur, a second dose of tocilizumab could be administered but 
A

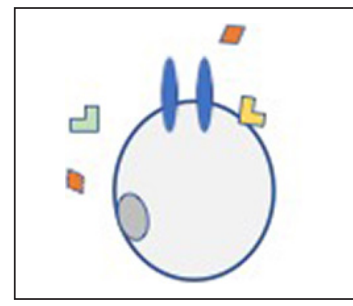

Inactivated JAK-STAT pathway

\section{Classic IL-6 signaling}

\section{Binding of IL-6} to membrane-bound IL-6R

B

Trans IL-6 signaling

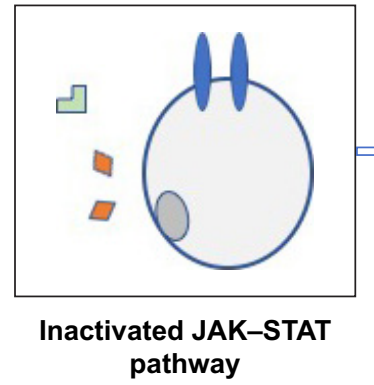

pathway

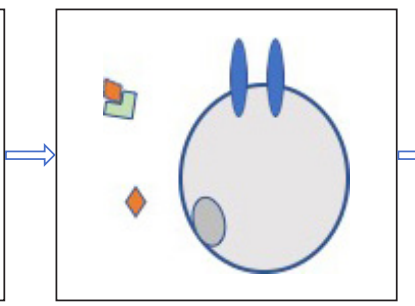

Binding of IL-6 to soluble IL-6R

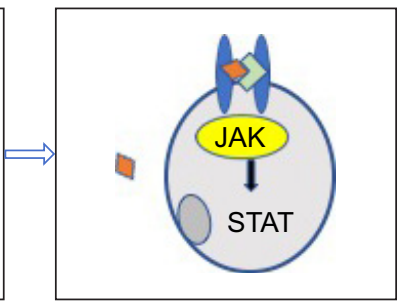

Binding of IL-6/sIL-6R to gp130 activates JAK-STAT pathway

\section{Tocilizumab blockade of membrane-bound receptor}

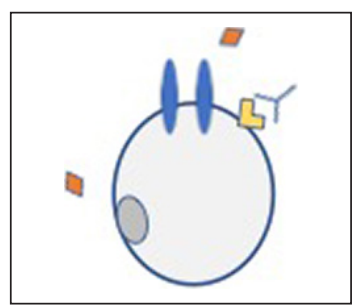

D Tocilizumab blockade of soluble receptor

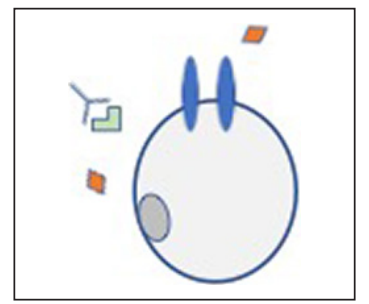

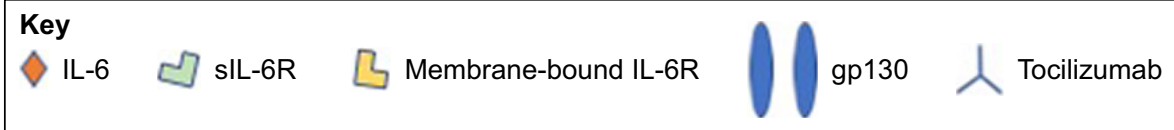

Figure 2 Mechanisms of IL- 6 signaling.

Notes: IL-6 potentiates its effects in one of two mechanisms. (A) Classic IL-6 signaling involves IL-6 binding to the high-affinity IL-6 receptor bound to the membrane of the effector cell. This in turn dimerizes gp I 30 resulting in JAK/STAT pathway activation. (B) Trans IL-6 signaling occurs at high serum IL-6 levels when it binds to the lower affinity slL-6R. This complex can dimerize gpI30 independent of the membrane-bound IL-6 receptor leading to JAK/STAT activation. (C, D) Tocilizumab, a monoclonal antibody, can inhibit IL-6 signaling by competing with IL- 6 for both the membrane-bound and soluble receptors.

Abbreviation: slL-6R, soluble IL-6 receptor.

a second-line agent should also be introduced simultaneously, such as a corticosteroid. ${ }^{9}$

Treatment approaches at other centers vary. The NCI Experimental Transplantation and Immunology Branch has created guidelines for treatment of CRS toxicities in adults, which are based on specific hemodynamic criteria and quantitative organ function thresholds as opposed to grade of CRS (Table 6). ${ }^{39}$ The Penn group utilizes tocilizumab first, corticosteroids second, and additional tocilizumab, siltuximab (monoclonal antibody to IL-6), or other anti-cytokine agents as a final treatment. ${ }^{40}$ It should be noted that siltuximab has not been sufficiently studied as a treatment for CRS and its use remains investigational. The Penn group does not offer suggestions as to when any of these therapies should be implemented. Neelapu et al state that management of CRS in adults is based on the CRS guidelines of Lee et al (Figure 4). ${ }^{28}$ Key differences 


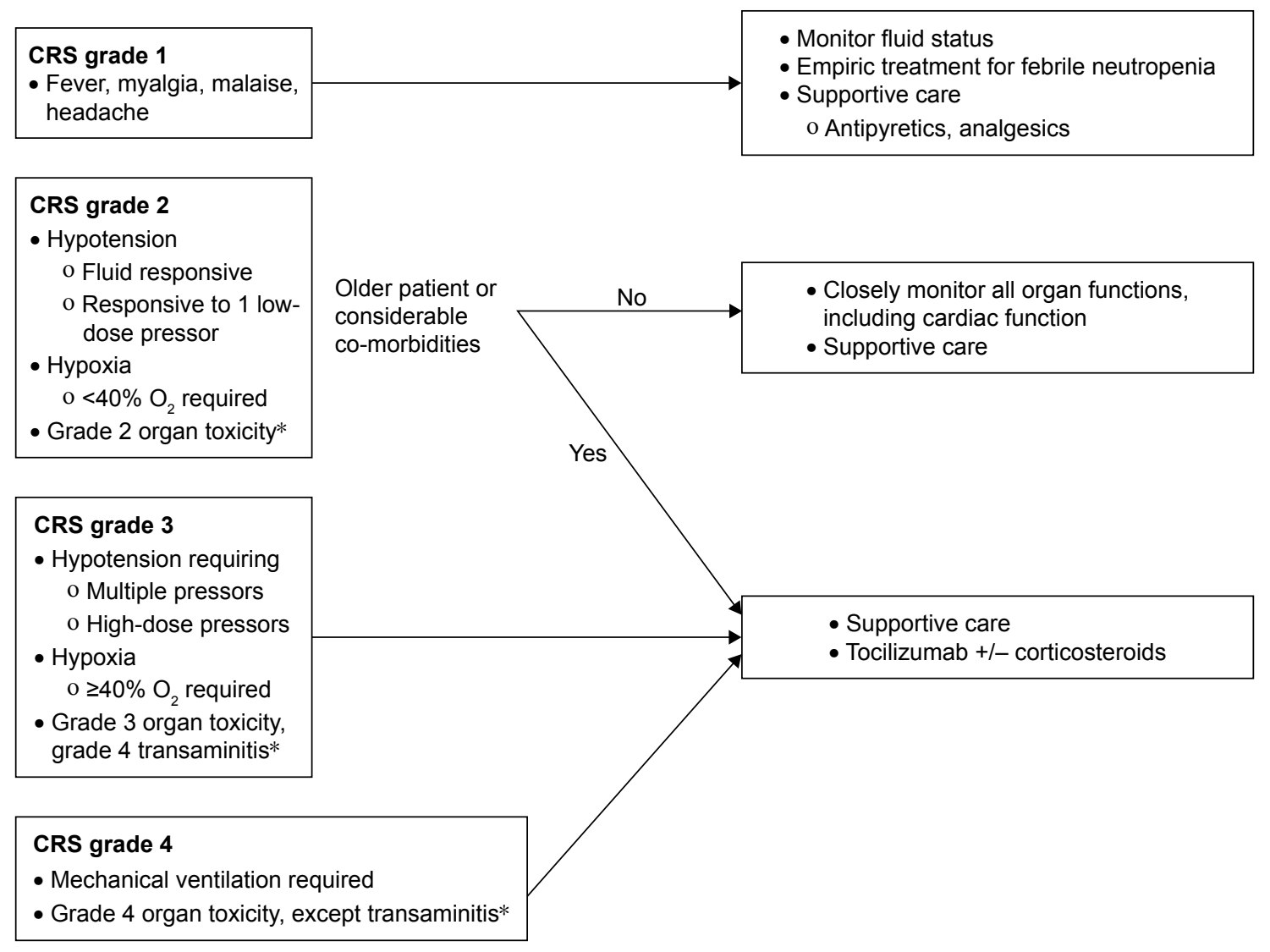

Figure 3 CRS management algorithm by Lee et al.9

Notes: The Lee criteria were designed in such a way so that grading can be tied to a management algorithm. Supportive care is the backbone of therapy with anti-cytokine therapy in the form of tocilizumab with or without corticosteroids implemented for grade 3 or higher CRS or for grade 2 in high-risk patients. *Grade of organ toxicities determined by CTCAE v4.03.

Abbreviations: CRS, cytokine release syndrome; CTCAE, Common Terminology Criteria for Adverse Events.

in therapeutic approach include the interchangeable use of siltuximab with tocilizumab despite the fact that tocilizumab is the only FDA-approved drug for severe CRS, for instance, the use of tocilizumab or siltuximab for grade 1 CRS and the use of tocilizumab or siltuximab before any vasopressors, for any degree of hypoxia, and for any grade 2 organ dysfunction. By this system, practically every patient receiving CAR T cells will receive tocilizumab or siltuximab as the vast majority of responding patients have at least one fever, triggering the diagnosis of grade 1 CRS. This may lead to the unnecessary exposure to these very expensive agents and perhaps untoward and unnecessary side effects.

The question regarding very early use of anti-cytokine therapies and their effect on CRS and tumor response may

Table 6 CRS and CAR-associated neurotoxicity management by Brudno and Kochenderfer ${ }^{39}$

\begin{tabular}{|c|c|c|}
\hline \multicolumn{3}{|l|}{ Tocilizumab 4-8 mg/kg (max $800 \mathrm{mg}$ ) } \\
\hline $\begin{array}{l}\text { Systolic blood pressure }<90 \mathrm{mmHg} \\
\text { despite norepinephrine }\end{array}$ & $\begin{array}{l}\text { Norepinephrine }>2 \mu \mathrm{g} / \mathrm{min} \text { beyond } \\
48 \text { hours }\end{array}$ & $\mathrm{FiO}_{2}>\mathbf{5 0} \%$ for more than 2 hours \\
\hline Left ventricular ejection fraction $<40 \%$ & Creatinine $>2.5$-fold increase & Impending intubation \\
\hline aPTT $>2 \times$ ULN & Significant bleeding & Creatine kinase $>5 \times$ ULN for more than 2 days \\
\hline \multicolumn{3}{|c|}{ Methylprednisolone I-2 mg/kg every 12 hours } \\
\hline \multicolumn{3}{|l|}{ CRS toxicity not responsive to tocilizumab } \\
\hline \multicolumn{3}{|c|}{ Dexamethasone $10 \mathrm{mg}$ every 6 hours $(\max 8$ doses or resolves to $\leq$ grade $\mathrm{I}$ ) } \\
\hline $\begin{array}{l}\text { Grade } 3 \text { NT (except headache) } \\
\text { lasting }>24 \text { hours }\end{array}$ & Grade $4 \mathrm{NT}$, any duration & Any generalized seizure \\
\hline
\end{tabular}

Abbreviations: CRS, cytokine release syndrome; CAR, chimeric antigen receptor; aPTT, activated partial thromboplastin time; ULN, upper limit of normal; NT, neurotoxicity. 

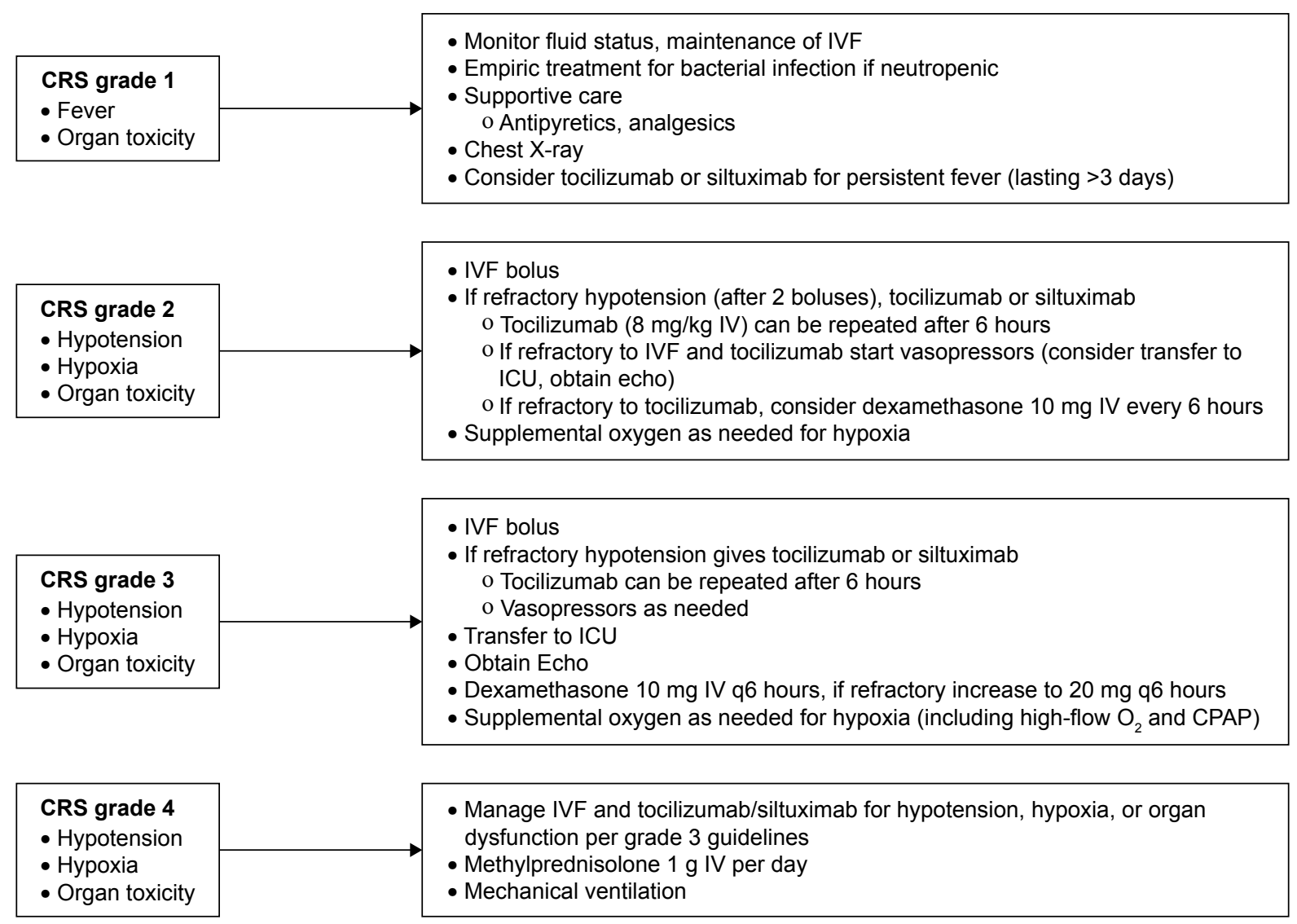

Figure 4 CRS management recommendations by Neelapu et al. ${ }^{28}$

Notes: These recommendations suggest using anti-cytokine therapies for grade I CRS and require them for grade 2 or higher CRS. Supportive care is also suggested for each grade.

Abbreviation: CRS, cytokine release syndrome; IVF, intravenous fluid; ICU, intensive care units; q, every; CPAP, continuous positive airway pressure.

be answered by the group at Seattle Children's Hospital. They are systematically studying the use of tocilizumab and corticosteroids administered at the first fever. This study is ongoing and additional data are pending (personal communication : Rebecca Gardner, May 4, 2018). Finally, the 2018 Lee/Santomasso CRS consensus manuscript did not address CRS treatment or timing of interventions, and it remains to be seen how the community will utilize this scale for such.

Managing CRS remains a therapeutic challenge and will be different depending on the type of CAR used, patient comorbidities, patient age, disease burden, cumulative exposure to prior therapies or bone marrow transplant, and kinetics of CRS onset and progression. Sound clinical judgment should always be utilized.

\section{Alternatives to tocilizumab}

Sarilumab is a monoclonal antibody with high affinity for the IL-6R that is FDA-approved for rheumatoid arthritis and is being investigated in clinical trials in other rheumatologic conditions. ${ }^{41}$ Despite this, sarilumab has not been utilized in the management of severe CRS.
Corticosteroids have been successfully used in the treatment of CRS, as both first- and second-line treatment. Many times, only short courses of corticosteroids are required. ${ }^{12-20}$ Successful CAR T-cell therapy depends on survival and proliferation of the genetically engineered cytotoxic $\mathrm{T}$ cells in patients. Steroids are known to inhibit physiologic T-cell function. Early concerns for steroids abrogating the antitumor respons $\mathrm{e}^{40}$ have not been validated, at least when employed well after CAR T-cell activation, expansion, and initiation of tumor cytotoxicity. Patients receiving even very high doses such as methylprednisolone at $2 \mathrm{mg} / \mathrm{kg} / \mathrm{day}$ for 2-4 days at the peak of CRS still demonstrate a clinical response to CAR T-cell therapy. ${ }^{42,43}$ This may be due, in part, to the supra-physiologic T-cell activation that occurs when the CAR is engaged. However, prospectively collected data are not available, and this hypothesis has not been formally tested. In addition, it remains to be seen whether very early (ie, at time of first fever) or prophylactic intervention with corticosteroids will affect response or risk of severe toxicity.

Corticosteroids, rather than tocilizumab, should be used as frontline therapy for severe neurotoxicity, especially in the 
absence of the classic hemodynamic perturbations of CRS. Tocilizumab does not cross the blood-brain barrier ${ }^{44}$ (BBB) and results in transient elevated IL-6 levels in the serum, which is implicated in the pathogenesis of neurotoxicity. Thus, tocilizumab is not recommended for the primary management of isolated neurotoxicity.

Siltuximab is another monoclonal antibody that blocks IL-6 signaling by binding IL-6 itself and preventing it from activating immune effector cells through either the trans or cis mechanisms. ${ }^{38}$ Siltuximab has a higher affinity for IL-6 than tocilizumab has for the IL-6R making it an attractive tool in managing CRS. It has not been formally studied, however, and given that tocilizumab is FDA-approved for managing severe CRS, it is difficult to justify using siltuximab as first-line therapy at this time. Well-designed clinical trials to evaluate siltuximab in managing CRS are needed. However, should a patient not respond to tocilizumab and corticosteroids, then the use of siltuximab is encouraged. Further, since siltuximab effectively removes active IL-6 from circulation and since the siltuximab-IL- 6 complex is unlikely to cross the BBB, siltuximab may also have a role in the management of CAR T-cell-induced neurotoxicity. Again, formal studies are needed to test this hypothesis.

Management of CRS with cytokine-directed therapy against cytokines other than IL-6 has also been attempted. Etanercept and infliximab both target TNF $\alpha$, known to be elevated in CRS, and have been used with mixed results in treating severe CRS. ${ }^{919}$ These results infer that TNF $\alpha$ is not consistently elevated after CAR T-cell therapy as it is in other inflammatory syndromes. Anakinra, a recombinant and slightly altered form of the IL-1 receptor antagonist, may be helpful in a subset of patients with increased IL-1 $\alpha$, but this cytokine is also not consistently elevated in patients with severe CRS. ${ }^{10}$ Although IFN $\gamma$ is consistently elevated very early in severe CRS, it is not thought to be an ideal target due to its role in T-cell proliferation. ${ }^{40} \mathrm{Clinical}$-grade antagonizing antibodies to IFN $\gamma$ are also lacking, though fontolizumab has been tested in small studies for rheumatologic conditions. ${ }^{45,46}$

\section{Conclusion}

If the successes seen to date in refractory/relapsed ALL and NHL are any indication, CAR T-cell therapy will likely revolutionize the field of cancer treatment. However, to realize this potential, it is vital that life-threatening toxicities, such as CRS and neurotoxicity, are managed in an expedient and efficacious manner. The goal of CRS management is to prevent irreversible organ damage without diminishing antitumor efficacy. Tocilizumab, the first and only FDA-approved IL-6-receptor inhibitor for severe CRS, has transformed the treatment of CRS and is considered first-line therapy. It should be used early in patients developing severe CRS (grade 3 or 4). Areas of active investigation include its use soon after CAR T-cell infusion, especially in the absence of CRS symptoms, and other agents that interrupt IL-6 signaling. The current generally accepted sequence of agents to manage severe or life-threatening CRS include: 1) tocilizumab with or without corticosteroids, 2) high-dose corticosteroids if not already employed, and 3) other agents such as siltuximab or multiple tocilizumab doses. This is in contrast to isolated, severe neurotoxicity, which should be initially managed with corticosteroids rather than tocilizumab.

Ultimately, identifying those patients at highest risk of severe CRS or neurotoxicity prior to CAR T-cell administration will be a key determinant in safety as more CAR therapies are developed. The type of CAR T-cell infused, antigen burden, patient age, and comorbidities are just a few variables that modulate CRS risk. Utilizing biomarkers present before infusion to identify risk and intervention strategies after infusion would be valuable. Ongoing efforts are being made in this arena. In this article, we have discussed the pathophysiology and symptoms of CRS, CRS grading, the possibility of CRS prevention, and management of CRS. Multiple grading scales and treatment algorithms for CRS have been proposed, and although they are critical tools in the management of CRS, they are not a substitute for sound clinical judgment. Until more is known, timely intervention with tocilizumab with or without corticosteroids remains the best management strategy.

\section{Acknowledgment}

DWL receives support from a St Baldrick's Foundation Scholar Award.

\section{Disclosure}

DWL serves as a consultant for Juno Therapeutics, a Celgene company, and receives clinical trial support from Kite Pharma, a Gilead company. The other authors report no conflicts of interest in this work.

\section{References}

1. Nguyen K, Devidas M, Cheng SC, et al; Children's Oncology Group. Factors influencing survival after relapse from acute lymphoblastic leukemia: a Children's Oncology Group study. Leukemia. 2008;22(12):2142-2150.

2. Borowitz MJ, Devidas M, Hunger SP, et al; Children's Oncology Group. Clinical significance of minimal residual disease in childhood acute lymphoblastic leukemia and its relationship to other prognostic factors: a Children's Oncology Group study. Blood. 2008;111(12):5477-5485.

3. NIH National Cancer Institute. Late Effects of Treatment for Childhood Cancer (PDQ $\left.{ }^{\circledR}\right)-$ Health Professional Version. Available from: https:// www.cancer.gov/types/childhood-cancers/late-effects-hp-pdq. Accessed April 2, 2018 
4. Gökbuget N, Hoelzer D. Treatment of adult acute lymphoblastic leukemia. Hematology Am Soc Hematol Educ Program. 2006:133-141.

5. Hallek M. Chronic lymphocytic leukemia: 2017 update on diagnosis, risk stratification, and treatment. Am J Hematol. 2017;92(9):946-965.

6. Armitage JO. How I treat patients with diffuse large B-cell lymphoma. Blood. 2007;110(1):29-36.

7. Lee DW, Barrett DM, Mackall C, Orentas R, Grupp SA. The future is now: chimeric antigen receptors as new targeted therapies for childhood cancer. Clin Cancer Res. 2012;18(10):2780-2790.

8. Orentas RJ, Yang JJ, Wen X, Wei JS, Mackall CL, Khan J. Identification of cell surface proteins as potential immunotherapy targets in 12 pediatric cancers. Front Oncol. 2012;2:194.

9. Lee DW, Gardner R, Porter DL, et al. Current concepts in the diagnosis and management of cytokine release syndrome. Blood. 2014;124(2):188-195.

10. Teachey DT, Lacey SF, Shaw PA, et al. Identification of Predictive Biomarkers for Cytokine Release Syndrome after Chimeric Antigen Receptor T-cell Therapy for Acute Lymphoblastic Leukemia. Cancer Discov. 2016;6(6):664-679.

11. Suntharalingam G, Perry MR, Ward S, et al. Cytokine storm in a phase 1 trial of the anti-CD28 monoclonal antibody TGN1412. N Engl J Med. 2006;355(10):1018-1028.

12. Turtle CJ, Hanafi LA, Berger C, et al. Immunotherapy of non-Hodgkin's lymphoma with a defined ratio of $\mathrm{CD}^{+}$and $\mathrm{CD} 4^{+} \mathrm{CD} 19$-specific chimeric antigen receptor-modified T cells. Sci Transl Med. 2016;8(355): $355 \mathrm{ra} 116$.

13. Turtle CJ, Hanafi LA, Berger C, et al. CD19 CAR-T cells of defined CD4+:CD8+ composition in adult B cell ALL patients. J Clin Invest. 2016;126(6):2123-2138.

14. Lee DW, Kochenderfer JN, Stetler-Stevenson M, et al. T cells expressing CD19 chimeric antigen receptors for acute lymphoblastic leukaemia in children and young adults: a phase 1 dose-escalation trial. Lancet. 2015;385(9967):517-528.

15. Maude SL, Frey N, Shaw PA, et al. Chimeric antigen receptor T cells for sustained remissions in leukemia. N Engl J Med. 2014;371(16):1507-1517.

16. Schuster SJ, Svoboda J, Chong EA, et al. Chimeric Antigen Receptor T Cells in Refractory B-Cell Lymphomas. N Engl J Med. 2017; 377(26):2545-2554.

17. Park JH, Rivière I, Gonen M, et al. Long-Term Follow-up of CD19 CAR Therapy in Acute Lymphoblastic Leukemia. N Engl J Med. 2018; 378(5):449-459.

18. Kochenderfer JN, Dudley ME, Kassim SH, et al. Chemotherapy-refractory diffuse large B-cell lymphoma and indolent B-cell malignancies can be effectively treated with autologous $\mathrm{T}$ cells expressing an anti-CD19 chimeric antigen receptor. J Clin Oncol. 2015;33(6):540-549.

19. Grupp SA, Kalos M, Barrett D, et al. Chimeric antigen receptor-modified T cells for acute lymphoid leukemia. $N$ Engl J Med. 2013;368(16): 1509-1518.

20. Brentjens RJ, Davila ML, Riviere I, et al. CD19-targeted T cells rapidly induce molecular remissions in adults with chemotherapyrefractory acute lymphoblastic leukemia. Sci Transl Med. 2013;5(177): $177 \mathrm{ra38}$.

21. FDA approval brings first gene therapy to the United States: CAR T-cell therapy approved to treat certain children and young adults with B-cell acute lymphoblastic leukemia. Available from: https://www.fda. gov/NewsEvents/Newsroom/PressAnnouncements/ucm574058.htm. United States Food and Drug Administration Press Release. Accessed August 30, 2017.

22. FDA approves CAR-T cell therapy to treat adults with certain types of large B-cell lymphoma: Yescarta is the second gene therapy product approved in the U.S. Available from: https://www.fda.gov/NewsEvents/ Newsroom/PressAnnouncements/ucm581216.htm. United States Food and Drug Administration Press Release. Accessed October 18, 2017.

23. FDA approves tisagenlecleucel for adults with relapsed or refractory large B-cell lymphoma. Available from: https:/www.fda.gov/Drugs/ InformationOnDrugs/ApprovedDrugs/ucm606540.htm. United States Food and Drug Administration Press Release. Accessed May 1, 2018.
24. FDA approval brings first gene therapy to the United States. Available from: https://www.fda.gov/newsevents/newsroom/pressannouncements/ucm574058.htm. United States Food and Drug Administration Press Release. Accessed August 30, 2017.

25. US Department of Health and Human Services. Common Terminology Criteria for Adverse Events (CTCAE). V4.03. 2010. National Institutes of Health, Bethesda, MD. Available from: https://evs. nci.nih.gov/ftp1/CTCAE/CTCAE_4.03/CTCAE_4.03_2010-0614_QuickReference_5x7.pdf. Accessed March 21, 2018.

26. Davila ML, Riviere I, Wang X, et al. Efficacy and toxicity management of 19-28z CAR T cell therapy in B cell acute lymphoblastic leukemia. Sci Transl Med. 2014;6(224):224ra25.

27. Porter D, Frey N, Wood PA, Weng Y, Grupp SA. Grading of cytokine release syndrome associated with the CAR T cell therapy tisagenlecleucel. J Hematol Oncol. 2018;11(1):35.

28. Neelapu SS, Tummala S, Kebriaei P, et al. Chimeric antigen receptor T-cell therapy - assessment and management of toxicities. Nat Rev Clin Oncol. 2018;15(1):47-62.

29. US Department of Health and Human Services. Common Terminology Criteria for Adverse Events (CTCAE). V5.0. 2018. National Institutes of Health, Bethesda, MD. Available from: https://ctep.cancer.gov/protocoldevelopment/electronic_applications/docs/CTCAE_v5_Quick_ Reference_8.5x11.pdf. Accessed on March 09, 2018.

30. Lee DW, Santomasso BD, Locke FL, et al. ASBMT Consensus Grading for Cytokine Release Syndrome and Neurological Toxicity Associated with Immune Effector Cells. Biol Blood Marrow Transplant. Epub 2018 Dec 25.

31. Gust J, Hay KA, Hanafi LA, et al. Endothelial Activation and BloodBrain Barrier Disruption in Neurotoxicity after Adoptive Immunotherapy with CD19 CAR-T Cells. Cancer Discov. 2017;7(12): 1404-1419.

32. Norelli M, Camisa B, Barbiera G, et al. Monocyte-derived IL-1 and IL-6 are differentially required for cytokine-release syndrome and neurotoxicity due to CAR T cells. Nat Med. 2018;24(6):739-748.

33. Giavridis T, van der Stegen SJC, Eyquem J, Hamieh M, Piersigilli A, Sadelain M. CAR T cell-induced cytokine release syndrome is mediated by macrophages and abated by IL-1 blockade. Nat Med. 2018;24(6):731-738.

34. Taraseviciute A, Tkachev V, Ponce R, et al. Chimeric Antigen Receptor T Cell-Mediated Neurotoxicity in Nonhuman Primates. Cancer Discov. 2018;8(6):750-763.

35. Jin Z, Xiang R, Qing K, et al. The severe cytokine release syndrome in phase I trials of CD19-CAR-T cell therapy: a systematic review. Ann Hematol. Epub 2018 May 15.

36. Gardner RA, Finney O, Annesley C, et al. Intent-to-treat leukemia remission by CD19 CAR T cells of defined formulation and dose in children and young adults. Blood. 2017;129(25):3322-3331.

37. Lee DW, Wayne AS. Chimeric antigen receptor (CAR) T cells. In: Ascierto PA, Stroncek DF, Wang E, editors. Developments in T Cell Based Cancer Immunotherapies. Switzerland: Springer; 2015.

38. Rose-John S. IL-6 trans-signaling via the soluble IL-6 receptor: importance for the pro-inflammatory activities of IL-6. Int J Biol Sci. 2012;8(9):1237-1247.

39. Brudno JN, Kochenderfer JN. Toxicities of chimeric antigen receptor T cells: recognition and management. Blood. 2016;127(26): 3321-3330.

40. Maude S, Barrett D, Teachey DT, Grupp SA. Managing Cytokine Release Syndrome Associated With Novel T Cell-Engaging Therapies. Cancer J. 2014;20(2):119-122.

41. Lamb YN, Deeks ED. Sarilumab: a review in moderate to severe rheumatoid arthritis. Drugs. 2018;78(9):929-940.

42. Maude SL, Teachey DT, Porter DL, Grupp SA. CD19-targeted chimeric antigen receptor T-cell therapy for acute lymphoblastic leukemia. Blood. 2015;125(26):4017-4023.

43. Mueller KT, Waldron ER, Grupp SA, et al. Clinical pharmacology of tisagenlecleucel in B-cell acute lymphoblastic leukemia. Clin Cancer Res. Epub 2018 Sep 6. 
44. Nellan A, McCully CML, Cruz Garcia R, et al. Improved CNS exposure to tocilizumab after cerebrospinal fluid compared to intravenous administration in rhesus macaques. Blood. 2018;132(6):662-666.

45. ClinicalTrials.gov. Identifier NCT00281294. A Phase 2 Study to Evaluate the Safety, Tolerability, and Activity of Fontolizumab in Subjects with Active Rheumatoid Arthritis. Bethesda (MD): National Library of Medicine (US); 2000. Available from: https://www.clinicaltrials.gov/ct2/ show/NCT00281294?term=NCT00281294\&rank=1. Accessed Jan 24, 2006.
46. Reinisch W, de Villiers W, Bene L, et al. Fontolizumab in moderate to severe Crohn's disease: a phase 2, randomized, double-blind, placebocontrolled, multiple-dose study. Inflamm Bowel Dis. 2010;16(2):233-242.

Therapeutics and Clinical Risk Management

\section{Publish your work in this journal}

Therapeutics and Clinical Risk Management is an international, peerreviewed journal of clinical therapeutics and risk management, focusing on concise rapid reporting of clinical studies in all therapeutic areas, outcomes, safety, and programs for the effective, safe, and sustained use of medicines. This journal is indexed on PubMed Central, CAS,
EMBase, Scopus and the Elsevier Bibliographic databases. The manuscript management system is completely online and includes a very quick and fair peer-review system, which is all easy to use. Visit http://www.dovepress.com/testimonials.php to read real quotes from published authors.

Submit your manuscript here: http://www.dovepress.com/therapeutics-and-clinical-risk-management-journal 